\title{
Studies of Interactions of Valsartan, Glimepiride and Ciprofloxacin HCl by DSC and HPLC
}

\author{
Mohammad Farhadur Rahman ${ }^{1}$, Md. Abdus Salam ${ }^{1}$ Asma Rahman² \\ and Md. Zakir Sultan ${ }^{2}$ \\ ${ }^{1}$ Department of Chemistry, University of Dhaka, Dhaka-1000, Bangladesh \\ ${ }^{2}$ Centre for Advanced Research in Sciences, University of Dhaka, Dhaka-1000, Bangladesh
}

Received: June 10, 2017; Accepted: June 29, 2017; Published (Web): July 31, 2017

\begin{abstract}
This article deals with the results of in vitro interactions among glimepiride, ciprofloxacin $\mathrm{HCl}$ and valsartan at the molar ratio of 1:1:1 by DSC and HPLC method. The DSC thermogram of the mixture (glimepiride, ciprofloxacin $\mathrm{HCl}$ and valsartan) showed different melting endotherm than the melting endotherm for standard valsartan, ciprofloxacin $\mathrm{HCl}$ and glimepiride. Since the melting endotherms of mixture and individual drugs were not identical, it demonstrated the presence of interactions among the drugs. This result was further verified by HPLC to observe their recovery range. The \% recovery ranges were found as $25.33,23.49$ and $135.82 \%$ for glimepiride, ciprofloxacin $\mathrm{HCl}$ and valsartan, respectively. The abnormal percentage recovery range and peak areas fluctuation further indicated the interactions among glimepiride, ciprofloxacin $\mathrm{HCl}$ and valsartan.
\end{abstract}

Key words: Drug-Drug Interaction, Glimepiride, Ciprofloxacin $\mathrm{HCl}$, Valsartan, DSC, HPLC.

\section{Introduction}

Concurrent administration of more than one drug is a common practice in medical science, although one drug may interact with another. This interaction may be either synergistic or antagonistic or may lead to toxic effects. However, interactions may also exist between drugs and foods (drug-food interactions). These interactions may occur out of accidental misuse or due to lack of knowledge about the active ingredients involved in the relevant substances (National Prescribing Service, 2009; Kristensen, 1976). Patients with diseases like kidney/heart transplantation or failure, diabetes mellitus and hypertension, anemia, bone and lipid disorders and so on are frequently prescribed numerous medications. Concomitant use of a large number of medications may have increased risks for drug-drug interactions. The effects of a moderate interaction may cause deterioration in the patient's clinical status, resulting in additional treatment, hospitalization, and/or an extended hospital stay or life-threatening or permanent damage (Brouwers, 1992; Hansten and Horn, 1989).

Knowledge of drug interactions may allow early recognition and prevention of adverse consequences. However, to take any step to manage the problems of informations the nature of interaction should be known (Ahsan et al., 2011). For the drugs which are being used conventionally, interaction studies are also very important to detect the problems yet to be known.

Now-a-days, it is common phenomenon that most of the patients are affected by hypertension, diabetic and infection at the same period of time. Glimepiride is frequently prescribed with ciprofloxacin $\mathrm{HCl}$ and valsartan for concomitant use in patients suffering from diabetes, infections and hypertension in Bangladesh. These drugs may exhibit effects independently or may interfere or interact with each other. Valsartan is widely used in treatment

Correspondence to: Md. Zakir Sultan; Tel.: +880-2-9661900; extn-4722; E-mail: zakir.sultan@du.ac.bd

${ }^{\Psi}$ Present address: Department of Chemistry, Bangladesh University of Textiles, Dhaka-1208, Bangladesh 
of diseases like hypertension, heart failure, myocardial infarction and diabetic nephropathy (Criscione et al., 1995; Psaty et al., 1997; Cohn and Tognoni, 2001). Ciprofloxacin $\mathrm{HCl}$ is used to fight bacterial infections in the body. It is also used for the treatment of infections caused by specific pathogens known to be sensitive (Ahsan et al., 2012). In 2010 over 20 million outpatient prescriptions were written for ciprofloxacin, making it as the $35^{\text {th }}$ most commonly prescribed drug, and the $5^{\text {th }}$ most commonly prescribed antibacterial, in USA (Müller et al., 1995; Langtry and Balfour, 1998). The primary mechanism of action of glimepiride in lowering blood glucose appears to be dependent on stimulating the release of insulin from functioning pancreatic beta cells. The structures of the drugs are shown in figure 1.<smiles>CCC1=C(C)CN(C(=O)NCCc2ccc(S(=O)(=O)NC(=O)N[C@H]3CC[C@H](C)CC3)cc2)C1=O</smiles>

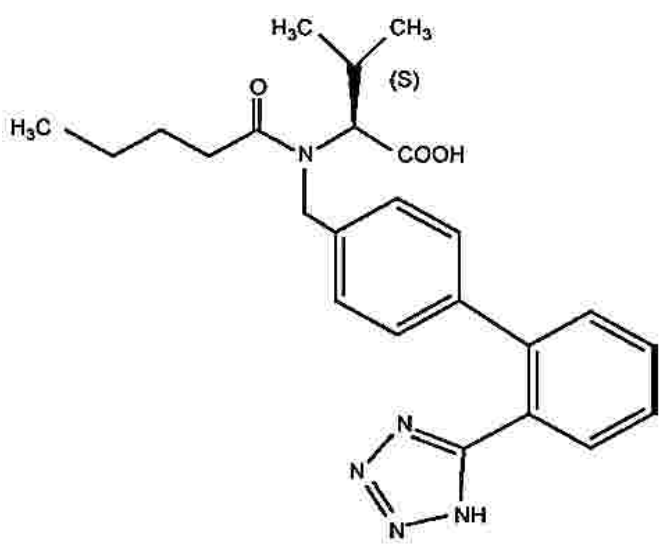

(B)<smiles>CCN(/C=C(/C(=O)O)C(O)/C=C/C(F)=C(/F)C1CCNCCN1)C(C)C</smiles>

(C)

Figure 1. Structure of glimepiride (A), valsartan (B) and ciprofloxacin $\mathrm{HCl}$ (C).

In his article, we report the drug-drug interactions of some commonly used drugs that are frequently prescribed in Bangladesh for the benefits of the patients by using DSC and HPLC, which are most commonly used to determine the drug-drug interactions (Pignatello and Francesco, 2011; Serafini et al., 2012; Arayne et al., 2010).

\section{Materials and Methods}

Drugs and reagents: Working standards glimepiride (potency: 95.41\%), ciprofloxacin $\mathrm{HCl}$ (potency: 94.23\%) and valsartan (potency: 99.9\%) were collected. HPLC grade acetonitrile, methanol and glacial acetic acid were purchased from Active Fine Chemicals Ltd., Dhaka, Bangladesh.

Instrumentation: Differential Scanning Calorimeter (DSC) (Model: DSC-60 WS, Shimadzu 
Corporation, Japan) was used for recording DSC thermograms. HPLC (model: UFLC Prominence, Shimadzu Corporation, Japan) on Phenomenex C-18 $(4.6 \times 250 \mathrm{~mm}, 5 \mu \mathrm{m})$ column equipped with an auto sampler (Model-SIL 20AC HT) and UV-Visible detector (Model-SPD 20A) was used for the analyses. The data was recorded using LC-solutions software.

\section{Experiment}

DSC method: Five mg drug mixture (mixture of valsartan, glimepiride and ciprofloxacin $\mathrm{HCl}$ at a molar ratio of 1:1:1) was weighed and mixed properly to make a solid homogeneous mixture in a watch glass. From this mixture $2.70 \mathrm{mg}$ was taken into aluminum pan and sealed properly, and the thermogram was taken from DSC 60, Shimadju, Japan. The temperature range of DSC runs for mixture and standards were $30{ }^{\circ} \mathrm{C}$ to $350{ }^{\circ} \mathrm{C}$. Experiment was performed under nitrogen gas at a flow rate of $20 \mathrm{ml} / \mathrm{min}$ and increase in temperature by $10^{\circ} \mathrm{C} / \mathrm{min}$.

HPLC method: Twenty $\mathrm{ml}$ of acetic acid was taken and added into distilled water, and the solution was made up to $1000 \mathrm{ml}$ to get the solution of $2 \%$ acetic acid. Then it was sonicated for 10 minutes. The chromatographic conditions was developed by using a C-18 bonded silica column ( $250 \times 4.60 \mathrm{~mm}, 5 \mu$, Phenomenex, Inc) with a mobile phase comprising of $2 \%$ acetic acid and acetonitrile $(40: 60, \mathrm{v} / \mathrm{v})$ with flow rate $0.70 \mathrm{ml} / \mathrm{min}$ at wavelength of $240 \mathrm{~nm}$.

Preparation of standard and sample solutions: Thirty mg of each drug was weighed and taken in a $100 \mathrm{~mL}$ volumetric flask. At first the drugs were dissolved separately in $50 \mathrm{ml}$ mixture of acetonitrile and distilled water (50:50) and the volume was adjusted to $100 \mathrm{ml}$ with the same solvent. The concentration of the each solution was $100 \mu \mathrm{g} / \mathrm{ml}$. The stock solutions were diluted by serial dilution procedure to get the concentrations in the range of $80 \%-120 \%$. Five $\mathrm{mg}$ from the solid homogeneous mixture was taken into a test tube and dissolved in methanol. The sample mixture was filtered using 0.45 $\mu \mathrm{m}$ syringe filter. In the similar way the standard solutions were also prepared.
Calibration curve: To get the individual calibration curve of each drug, five different concentration levels $(40,45,50,55$ and $60 \mu \mathrm{g} / \mathrm{ml})$ were prepared from standard solution by $50 \%$ distilled water and $50 \%$ acetonitrile. Then $20 \mu \mathrm{L}$ from each solution was injected into the HPLC using autosampler and the analyses were monitored at 240 $\mathrm{nm}$ and repeated three times. The average peak areas were plotted against concentrations.

\section{Results and Discussion}

DSC method for drug-drug interaction analysis: The DSC is a reliable method for the study and detection of drug-drug interactions. The DSC thermograms of the mixture (glimepiride, ciprofloxacin $\mathrm{HCl}$ and valsartan) and individual drugs were carried out at the temperature range of $30^{\circ} \mathrm{C}$ to $350^{\circ} \mathrm{C}$. The DSC thermograms of the mixture showed sharp melting endotherm at $104.13^{\circ} \mathrm{C}, \quad 154.89^{\circ} \mathrm{C}$ and $290.07^{\circ} \mathrm{C}$ which corresponded to its melting with normalized energy of $-1.14 \mathrm{~mW} / \mathrm{mg},-1.34 \mathrm{~mW} / \mathrm{mg}$ and $-2.26 \mathrm{~mW} / \mathrm{mg}$, respectively (Figure 2). The individual melting endotherms for valsartan, ciprofloxacin $\mathrm{HCl}$ and glimepiride were found at $117^{\circ} \mathrm{C}, 152.65^{\circ} \mathrm{C}$ and $213.85^{\circ} \mathrm{C}$, respectively. The melting endotherms of the physical mixture and individual drugs were not identical which represented the identity of a different product. That means bond breaking and forming to yield a new product indicated the presence of strong drug interactions among the drugs.

HPLC method for drug-drug interaction analysis: The HPLC analytical condition for mixture and the individual drugs (glimepiride, valsartan and ciprofloxacin $\mathrm{HCl}$ ) was developed by using the mobile phase (2\% acetic acid and acetonitrile, 40:60 $\mathrm{v} / \mathrm{v}$ ) at a flow rate of $0.7 \mathrm{~mL} / \mathrm{min}$. The injection volume was $20 \mu \mathrm{L}$ for standards and sample. Before analysis, every standard and sample was filtered through $0.45 \mu \mathrm{m}$ filter tips. The mobile phase was also filtered, sonicated and degassed before use. The column eluate was monitored with a UV detector at $240 \mathrm{~nm}$. All analyses were done at ambient temperature under isocratic conditions. The retention 
times found for standard ciprofloxacin $\mathrm{HCl}$, valsartan and glimepiride were at $2.77 \pm 0.1 \mathrm{~min}, 8.58 \pm 0.1$ $\mathrm{min}$ and $13.81 \pm 0.1 \mathrm{~min}$, respectively.

Calculation of percentage (\%) recovery: Linearity: The linearity of each drug was evaluated by using calibration curves to calculate the coefficient of correlation and intercept values. The calculated value for linearity from the calibration curve of ciprofloxacin $\mathrm{HCl}$, valsartan and glimepiride were $0.9991,0.9993$ and 0.9981 , respectively (Table 1, Figure 3).

The presence of interaction might be clear from the percentage recovery range of those drugs in the mixture. The \% recovery ranges were found as $23.49 \%, 25.33 \%$ and $135.82 \%$ for ciprofloxacin $\mathrm{HCl}$, glimepiride and valsartan, respectively. The abnormal recovery range might be due to chemical bonds broken in liquid stage of mixture drugs. This indicated interaction among the drugs.

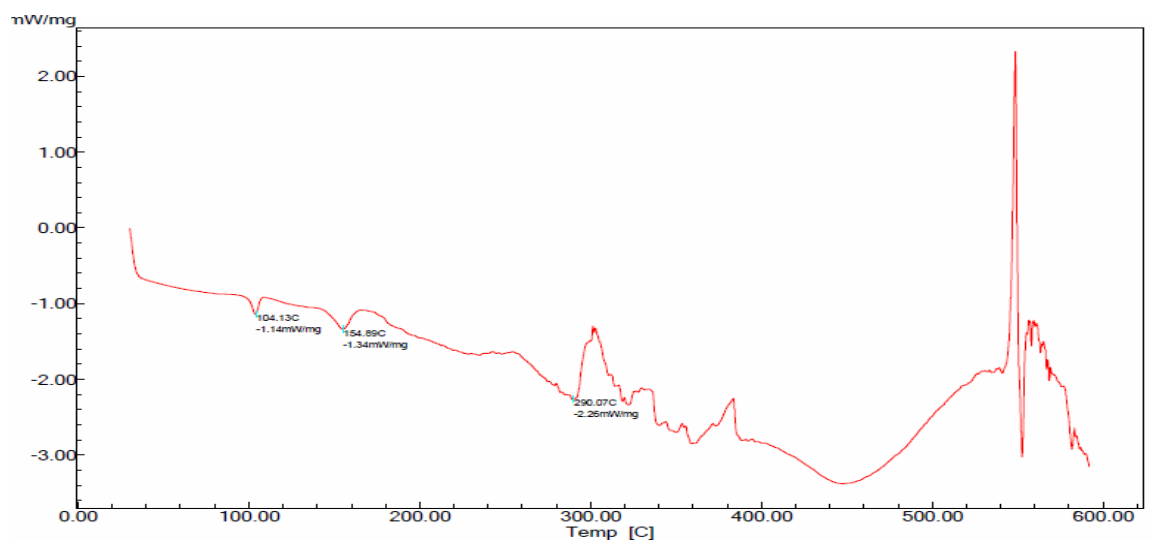

(A)

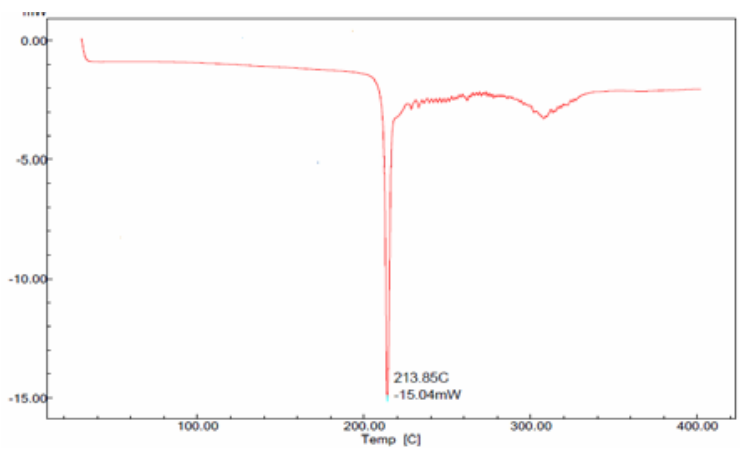

(B)

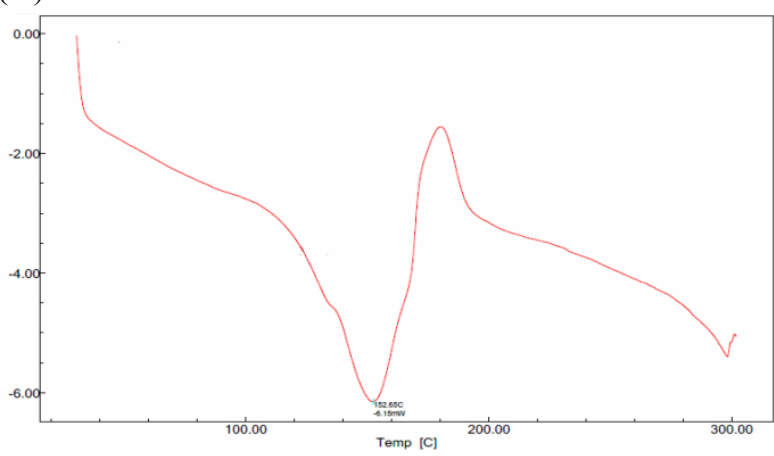

(C)

Figure 2. The DSC thermogram of the mixture (A), glimepiride (B) and ciprofloxacin $\mathrm{HCl}(\mathrm{C})$.

Table 1. Peak area at various concentrations for ciprofloxacin $\mathrm{HCl}$, valsartan and glimepiride.

\begin{tabular}{cccc}
\hline \multirow{2}{*}{$\begin{array}{c}\text { Concentration } \\
\mu \mathrm{g} / \mathrm{ml}\end{array}$} & Ciprofloxacin HCl & Valsartan & Glimepiride \\
\cline { 2 - 4 } & 1373846 & 2168012 & 2403059 \\
40 & 1555455 & 2486791 & 2819468 \\
50 & 1708820 & 2766916 & 3197840 \\
55 & 1863761 & 3101487 & 3558440 \\
60 & 2024659 & 3383738 & 3889408 \\
\hline
\end{tabular}




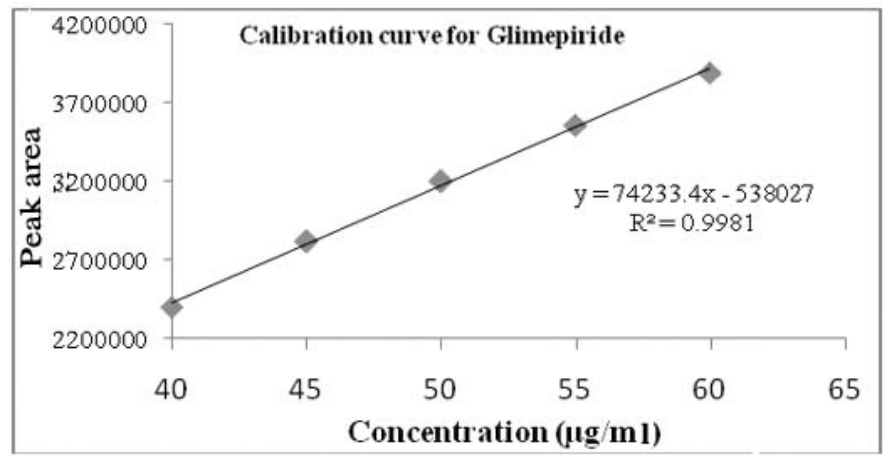

(A)

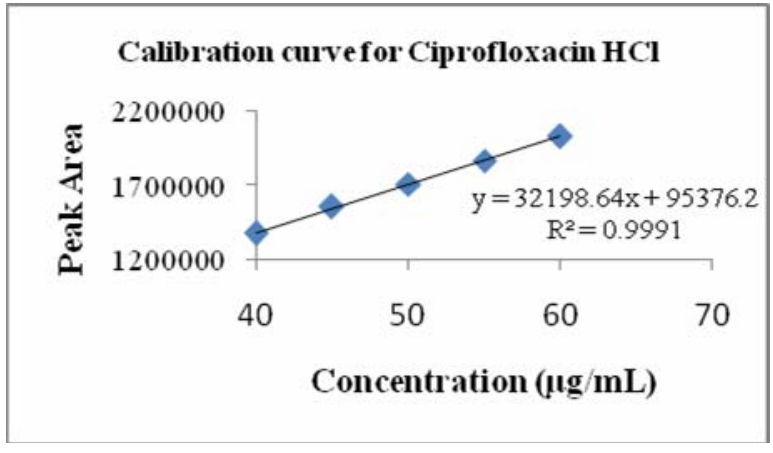

(B)

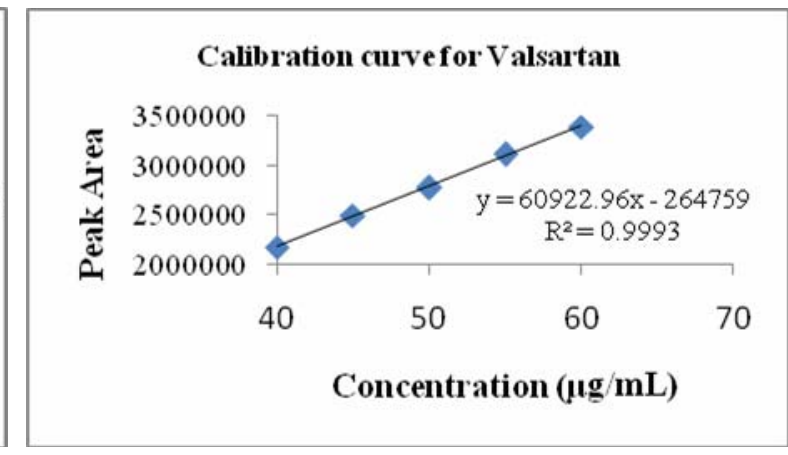

(C)

Figure 4. Calibration curve and linearity of glimepiride (A), ciprofloxacin $\mathrm{HCl}(\mathrm{B})$ and valsartan (C).

$\mathrm{uV}$

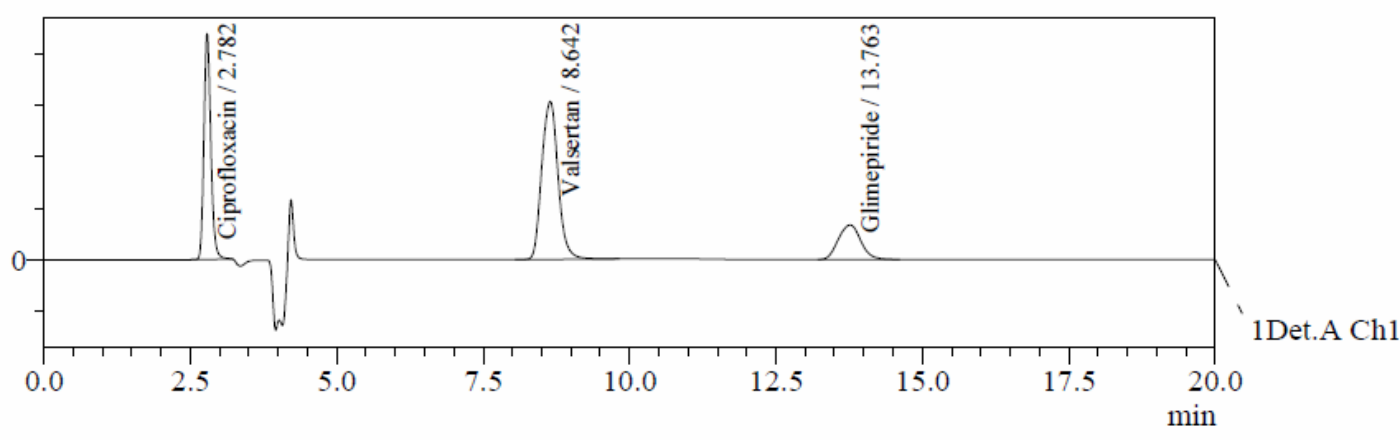

1 Det.A Ch1 / 240nm

Figure 3. Chromatogram for mixture at $240 \mathrm{~nm}$.

\section{Conclusion}

Knowledge of drug-drug interactions may allow early recognition and prevention of adverse consequences. The most comprehensive understanding of clinically significant drug interaction can be achieved by combining knowledge of the mechanism of drug interaction with recognition of the high-risk patients and the identification of drug with a narrow therapeutic index. Problems arising from the interaction of drugs may be overcome by partial changes in the molecular pattern, by blocking the reactive site in the molecule, by changing the dosage regimen or by avoiding the combined application of the interacting drugs. However, to take any step to manage the interaction problems, the nature of interaction should be known. 
It is important to know the possible interactions of a new drug prior to use clinically. For drugs which are being used conventionally, interaction studies are also very important to detect the problems yet to be known.

In course of research works, the antidiabetic, antiinflammatory and antihypertensive drugs were used to study the interactions among the drugs. For detection of drug- drug interactions, reliable DSC and HPLC methods were used. The present study revealed a clear indication of interaction among glimepiride, valsartan and ciprofloxacin $\mathrm{HCl}$ in both DSC and HPLC method. However, this was a preliminary study and more extensive investigations should be conducted to have conclusive remarks.

\section{References}

Ahsan, M. R., Sultan, M. Z., Amjad, F. M., Sultana, S., Baki, M. A., Hossain, M. A. and Amran, S. M. 2012. The study of in vitro interaction of ciprofloxacin with paracetamol and zinc in aqueous medium. J. Sci. Res. 4, 701-708.

Ahsan, M. R., Sultan, M. Z., Baki, M. A., Rahman, M. A., Hossain, M. A., and Amran, M. S. 2011. The study of in vitro and in vivo effects of concurrent administration of paracetamol and zinc on the antibacterial activity of ciprofloxacin. Dhaka Univ. J. Pharm. Sci. 10, 137-142.

Arayne, M.S., Sultana, N., Zuberi, M.H. and Urooj Haroon, U. 2010. In vitro studies of interaction between metformin and NSAIDS (Non Steroidal AntiInflamatory Drugs) using spectrophotometry and RPHigh Performance Liquid Chromatography. J. Chil. Chem. Soc. 55, 206-2011.

Brouwers, J.R.B.J. 1992. Drug interactions with quinolone antibacterials. Drug Safety 7, 268-281.
Cohn, J.N. and Tognoni G. 2001. A randomized trial of the angiotensin-receptor blocker valsartan in chronic heart failure. N. Engl. J. Med. 345, 1667-1675.

Criscione, L., Bradley, W., Buhlmayer, P., Whitebread, S.,Glazer, R., Lloyd, P., Mueller, P. and Gasparo, M.D. 1995. Valsartan: preclinical and clinical profile of an antihypertensive angiotensin-II antagonist. Cardiovasc. Drug Rev. 13, 230-250.

Hansten, P.D. and Horn, J.R., 1989. Drug interactions: Clinical Significance of Drug-drug Interaction, 6th edition, Philadelphia, pp. 5-13.

Kristensen, M.B. 1976. Drug interaction and clinical pharmacokinetics, Clin. Pharmacokin, 1, 351-372.

Langtry, H.D. and Balfour, J.A. 1998. Glimepiride: a review of its use in the management of type 2 diabetes mellitus. Drugs 55, 563-584.

Müller, G., Satoh Y. and Geisen, K. 1995. Extrapancreatic effects of sulfonylureas: a comparison between glimepiride and conventional sulfonylureas. Diabet. Res. Clin. Pract. 28 (Suppl. 28), S115-S137.

National Prescribing Service. 2009. Available at: http://nps.org.au/news_and_media/media_releases/rep ository/Forget_the_colour_shape_or_brand_its

Pignatello, R. and Francesco Castelli, F. 2011. Calorimetric techniques to study the interaction of drugs with biomembrane models. Pharm. Bioallied Sci. 3, 1-2.

Psaty, B.M., Smith, N.L., Siscovick, D.S., Koepsell, T.D., Weiss, N.S., Heckbert, S.R., et al., 1997. Health outcomes associated with antihypertensive therapies used as first-line agents. A systematic review and meta-analysis. JAMA 277, 739-745.

Serafini, M.R., Menezes, P.P., Costa, L.P., Lima, C.M., Quintans Jr, L.J., Cardoso, J.C., Matos, J.R., SoaresSobrinho, J.L., Grangeiro Jr, S., Nunes, P.S., Bonjardim, L.R. and Araújo, A.A.S. 2012. Interaction of $p$-cymene with $\beta$-cyclodextrin. J. Therm. Anal. Calorim. 109, 951-955. 